Care: Jurnal Ilmiah Ilmu Kesehatan Vol .7, No.3, 2019, hal 97-107

Tersedia online di https://jurnal.unitri.ac.id/index.php/care

ISSN 2527-8487 (online)

ISSN 2089-4503 (cetak)

\title{
E-MONITORING INTERAKTIF MENINGKATKAN REFLEKSI DIRI, MOTIVASI BELAJAR DAN HASIL BELAJAR MAHASISWA DIII KEBIDANAN
}

\author{
Eka Ratnasari $^{1)}$, Wiryawan Permadi ${ }^{2)}$, Dany Hilmanto ${ }^{3)}$ \\ ${ }^{1)}$ Program Studi Magister Kebidanan FK Unpad \\ ${ }^{2}$ Departemen Obstetri dan Gynekologi FK Unpad \\ ${ }^{3}$ Departemen Ilmu Kesehatan Anak FK Unpad \\ E-mail :sarirssahudi@gmail.com
}

\begin{abstract}
The proportion of practice in Midwifery education has 60\% of capacity, more than the proportion of theories which is only 40\%. The biggest proportion of practice makes the Clinical Advisor and Academic Advisor try to provide immediate feedback to students in every skill learned in the practice field. Interactive, effective and corrective feedback can belp students to do self-reflection so while in the practice field students expected to be motivated to improve learning outcomes. The purpose of this study was to define the effect of Interactive EMonitoring implementation on self-reflection, motivation and learning outcomes of the student.A research population of this study is students of midwifery diploma program in thirdh semester of 2018/2019 Akademic year who take part in second Laboratory Learning Practices, which are spread over in 13 of independent midwife practice fields (PMB). Samples were taken in based on inclusion criteria, students who were guided by PK that included in the criteria and in aged 19-20 years were 56 students. Data analyzed, if the data is normally distributed then it uses paired $t$ test and if the data is not normally distributed then it uses the Wilcoxon Test.The results showed that students self-reflection increased from 74.9 to $80.5(p<0.005)$. Student learning motivation increased from 80.1 to $87.6(p<0.05)$ and learning outcomes increased from 61.8 to $68.4(p<0.05)$. The conclusion of this study is interactive e-monitoring implementation has influence on the increases in self-reflection, motivation and learning outcomes of D III of midwifery students. Need further research with a longer time for suggestions.
\end{abstract}

Keywords: Interactive E-Monitoring; Learning Outcomes; Learning Motivation and Self Reflection.

\begin{abstract}
ABSTRAK
Proporsi praktik dalam pendidikan Kebidanan memiliki kapasitas $60 \%$, lebih banyak dibandingkan proporsi teori yang hanya $40 \%$.Proporsi praktik yang lebih besar membuat Pembimbing Klinik (PK) dan Pembimbing Akademik (PA) harus berupaya memberikan umpan balik dengan segera kepada mahasiswa disetiap keterampilan yang dipelajari dilahan praktik.Pemberian umpan balik yang interaktif, efektif dan korektif dapat membantu

Cara mengutip: Ratnasari, Eka., Permadi, Wiryawan., \& Hilmanto, Dany. (2019). E-Monitoring Interaktif Meningkatkan Refleksi Diri, Motivasi Belajar dan Hasil Belajar Mahasiswa DIII Kebidanan. Care:Jurnal Ilmiah Ilmu Kesehatan, 7(3), 97-107


mahasiswa dalam melakukan refleksi diri sehingga harapannya mahasiswa mampu termotivasi untuk memperbaiki hasil pembelajaran selama di lahan praktik. Tujuan penelitian ini untuk mengetahui pengaruh penggunaan E-Monitoring Interaktif terhadap refleksi diri, motivasi dan hasil belajar mahasiswa.Penelitian ini adalah penelitian kuantitatif dengan rancangan kuasi eksperimen pre test-post test design. Populasi penelitian yaitu seluruh mahasiswa Prodi D3 Kebidanan semester III Tahun Akademik 2018/2019 yang mengikuti Praktik belajar Laboratorium (PBL) II yang tersebar di 13 lahan Praktik mandiri Bidan (PMB). Sampel diambil sesuai dengan kriteria inklusi yaitu mahasiswa yang dibimbing oleh PK yang termasuk kedalam kriteriadan yang berusia 19-20 tahun sebanyak 56 orang mahasiswa. Data dianalisis, jika data terdistribusi normal maka menggunakan uji-T berpasangan dan jika data tidak terdistribusi normal maka menggunakan Uji Wilcoxon.Hasil penelitian menunjukkan refleksi diri mahasiswa mengalami kenaikan dari 74,9 menjadi 80,5 $(\mathrm{p}<0,005)$. Motivasi belajar mahasiswa mengalami kenaikan dari 80,1 menjadi 87,6 ( $<<0,05)$ dan Hasil belajar mengalami kenaikan dari 61,8 menjadi $68,4 \quad(\mathrm{p}<0,05)$. Simpulan penelitian ini terdapat pengaruh penggunaan e-monitoring interaktif terhadap kenaikan refleksi diri, motivasi dan hasil belajar mahasiswa D3 Kebidanan. Saran perlu dilakukan penelitian lebih lanjut dengan waktu yang lebih lama.

Kata Kunci : E-Monitoring Interaktif; Hasil belajar; Motivasi belajar dan Refleksi diri.

\section{PENDAHULUAN}

Pendidikan kebidanan merupakan pendidikan vokasional yang memiliki karakteristik dan ciri khas yang mengutamakan penerapan aspek-aspek praktis yang didukung oleh teori yang tepat (Aipkind, 2018). Berdasarkan acuan dan peraturan yang terkait dengan kurikulum pendidikan Diploma (D) III Kebidanan sebanyak $40 \%$ teori dan 60\% praktik (Pusdiknakes, 2010). Untuk menghasilkan lulusan bidan yang memiliki keterampilan klinik yang kompeten diperlukan pembelajaran praktik klinik yang berulang sehingga pemberian diskusi dan koreksi terarah atau umpan balik dalam praktik klinik dapat diberikan kepada mahasiswa dengan teratur (Kurniawati, 2014). Bimbingan dan diskusi serta pemberian umpan balikdi lahan praktik dilakukan oleh pembimbing lahan. Pembimbing sangat berperan dalam memberikan bimbingan, melakukan pemantauan pengetahuan dan keterampilan, manjadi fasilitator dalam diskusi, menjadi evaluator dan motivator dengan memberikan umpan balik pada mahasiswa. Umpan balik yang efektif pada mahasiswa akan berdampak kepada proses pembelajaran. Mahasiswa jadi segera mengetahui kekurangan dan kelebihan yang dia lakukan dalam memberikan asuhan kepada klien. Namun, jika umpan balik tidak segera diberikan oleh pembimbing kepada mahasiswa, mahasiswa tidak akan mengetahui kekurangan atau kesalahan yang harus diperbaiki, sehingga memungkinkan mahasiswa untuk tidak memperbaiki 
kesalahan dalam melakukan tindakan ataupun asuhan (Levy LS, et.al, 2009).

Pemberian umpan balik yang interaktif, efektif dan korektif yang diberikan pembimbing kepada mahasiswa dapat membantu mahasiswa dalam melakukan refleksi diri terhadap proses belajar (Mariana GH, 1998).Refleksi diri tersebut sangat penting untuk mahasiswa tenaga kesehatan yang kesehariannya bekerja mengaplikasikan teori dan praktik kepada klien, sehingga mahasiswa harus belajar dalam menyadarikinerja profesionalitas diri (Oktaria D, 2015). Hal tersebut bertujuan untuk dapat mengetahui kelemahan dan kekuatan dirinya, dan kemudianmenyusun rencana tindaklanjut yang sesuai dengan tujuan untuk dapat memperbaiki kekurangan danmeningkatkan kemampuan diri (Poltekkes Bandung, 2003).Sehingga muncul dalam diri mahasiswa dorongan untuk meningkatkan pengetahuan dan keterampilannya agar lebih mendapatkan hasil belajar yang berubah ke arah yang lebih baik ataupun mahasiswa dapat mencapai target pembelajaran di lahan praktik sesuai dengan tujuan pembelajaran (Molloy E, 2013)

Peran pembimbing tersebut tidak selalu berfunsi secara baik.akan menjadi kendala jika dialami mahasiswa ketika di lahanpraktik (Nurhasanah, 2014). Kendala atau hambatan yang secara dasar di alami oleh mahasiswa yaitu mahasiswa tidak ada kesempatan lagi untuk mendapatkan umpan balik yang korektif dengan segera, tidak ada kemungkinan untuk menilai dan memonitor kemajuan mahasiswa, tidak ada konsistensi antara pemberian pembelajaran dikelas dan pembelajaran di lahan (Sari DWP, 2015).Agar hal tersebut dapat diatasi diperlukan metode untuk bisa memfasilitasi pembimbing dan mahasiswa dalam melaksanakan bimbingan atau diskusi dan pemberian umpan balik yang korektif dan efektif.Karena sejauh ini pemberian umpan balik hanya bersifat konvensional yaitu pembimbing praktik memberikan umpan balik sesuai dengan waktu yang dimiliki pembimbing.

Memanfaatkan kemajuan teknologi dengan aplikasi Edmodo sebagai E-Monitoring Interaktifsebagai upaya dalam memfasilitasi monitoring yang interaktif antara pembimbing dan mahasiswa dalam proses pemberian diskusi dan umpan balik dalam pembelajaran praktik klinik. Tujuan penelitian ini untuk mengetahui pengaruh penggunaan E-Monitoring Interaktif (emonif) terhadap refleksi diri,motivasi dan hasil belajar mahasiswa DIII Kebidanan pada kegiatan Praktik Belajar laboratorium (PBL) II.

\section{METODE PENELITIAN}

Penelitian ini menggunakan metode kuantitatif, untuk menjawab pengaruh variabel bebas terhadap variabel terikat. 
Variabel Bebas adalah Refleksi diri, motivasi belajar dan hasil belajar sebelum penggunaan E-Monitoring Interaktif variabel terikat adalah Refleksi diri, motivasi belajar dan hasil belajar Setelah penggunaan EMonitoring Interaktif. Jenis penelitian kuasi eksperimental dengan rancangan one group pre and post test design.yaitu dalam penelitian ini pre test diberikan kepada seluruh responden sebelum penggunaan e-monif untuk mengukur refleksi diri, motivasi belajar dan hasil belajar pada kegiatan PBL II dan post test dilaksanakan setelah penggunaan e-monif pada kegiatan PBL II. Analisis data yang digunakan, jika data terdistribusi normal analisis menggunakan uji t berpasangan, tetapi jika data tidak terdistribusi normal, maka uji menggunakan uji wilcoxon. Subjek penelitian adalah mahasiswa D3 Kebidanan STIKes Muhammadiyah Cirebon semester III yang sedang melaksanakan kegiatan PBL II di 13 lahan Praktik Mandiri Bidan (PMB) yang termasuk kedalam kriteria inklusi : tercatat sebagai mahasiswa aktif prodi DIII Kebidanan, pernah mengikuti kegiatan PBL I, lulus ujian praktik semester III, mengikuti kegiatan PBL II, memiliki telepon seluler berbasis smartphone, peserta bersedia menjadi responden penelitian. Kriteria Eksklusi : Kehadiran mengikuti proses kegiatan Pembelajaran $<100 \%$ dan pembimbing Klinik kedalam sampel penelitian. Pada penelitian ini juga terdapat kriteria Drop Out yaitu responden tidak menggunakan e-monif sesuai dengan intruksi, responden mengundurkan diri pada waktu penelitian dan responden tidakmengikuti salah satu tes yang dilaksanakanolehpeneliti, sehingga total responden yang berpartisipasi dalam penelitian ini sebanyak 56 responden. Pemberian pretest dilaksanakan 2 (dua) hari sebelum pelaksanaan kegiatan PBL yaitu pada tanggal 14 Desember 2018 dan pelaksanaan post test dilaksanakan 2 hari setelah kegiatan PBL yaitu tanggal 14 januari 2019. Pemberian intervensi dengan menggunakan e-monif dilahan praktik berlangsung selama 4 minggu. Frekuensi penggunaan e-monif setiap hari pada saat di lahan praktik. Mahasiswa harus melakukan kegiatan melalui e-monif tersebut dengan tujuan untuk mempermudah pemberian umpan balik setelah melaksanakan kegiatan.

Instrumen yang digunakan dalam penelitian ini berupa kuesioner refleksi diri dan motivasi belajar yang telah dilakukan uji validitas dan reabilitas terlebih dahulu dengan nilai $\mathrm{r}$ tabel $=0,444$. Hasil belajar diukur dengan menggunakan jenis soal pilihan ganda/Multiple Choice Question (MCQ) berbasis vignette dan soal telah melewati analisis butir soal dengan menggunakan Anatest. Penelitian ini sudah mendapat pembebasan etik dengan Nomor 1445/UN6.KEP/EC/2018 dari Komisi 
Etik Penelitian Universitas Padjadjaran Bandung.

\section{HASIL}

Tabel 1. Perbandingan Refleksi Diri Mahasiswa Sebelum dan Setelah Penggunaan E-Monif

\begin{tabular}{|c|c|c|c|}
\hline \multirow[t]{2}{*}{ Refleksi diri (skala 100) } & \multicolumn{3}{|c|}{ Ukuran Statistik } \\
\hline & $\bar{x}(\mathrm{SD})$ & Median & Rentang \\
\hline \multicolumn{4}{|l|}{ 1. Reaksi emosi } \\
\hline Pre & $73,2(14,1)$ & 72,2 & $38,9-100$ \\
\hline Post & $84,3(11,2)$ & 83,3 & $61,1-100$ \\
\hline \multicolumn{4}{|c|}{ Perbandingan Pre Vs Post Nilai $\mathrm{p}<0,001 *$} \\
\hline \multicolumn{4}{|c|}{ 2. Konten pikiran } \\
\hline Pre & $73,8(13,2)$ & 73,3 & $40,0-100$ \\
\hline Post & $76,5(13,7)$ & 73,3 & $46,7-100$ \\
\hline \multicolumn{4}{|c|}{ Perbandingan Pre Vs Post Nilai $\mathrm{p}=0,040^{*}$} \\
\hline \multicolumn{4}{|l|}{ 2. Penghindaran } \\
\hline Pre & $78,1(11,9)$ & 80,0 & $53,3-100$ \\
\hline Post & $79,8(14,1)$ & 80,0 & $33,3-100$ \\
\hline \multicolumn{4}{|c|}{ Perbandingan Pre Vs Post Nilai $\mathrm{p}=0,310^{*}$} \\
\hline \multicolumn{4}{|c|}{ Gabungan/perbandingan } \\
\hline Pre & $74,9(10,7)$ & 74,9 & $54,2-100$ \\
\hline Post & $80,5(9,8)$ & 81,2 & $54,2-100$ \\
\hline
\end{tabular}

Ket :*) Uji Wilcoxon, **) Uji t berpasangan

Tabel 2. Perbandingan Motivasi Belajar Mahasiswa Sebelum dan Setelah Penggunaan E-Monif

\begin{tabular}{|c|c|c|c|}
\hline \multirow[t]{2}{*}{ Motivasi belajar } & \multicolumn{3}{|c|}{ Ukuran Statistik } \\
\hline & $\bar{x}(\mathrm{SD})$ & Median & Rentang \\
\hline \multicolumn{4}{|l|}{ 1. Self efficacy } \\
\hline Pre & $80,2(10,0)$ & 83,3 & $58,3-100$ \\
\hline Post & $86,7(8,9)$ & 87,5 & $66,7-100$ \\
\hline \multicolumn{4}{|c|}{ Perbandingan Pre Vs Post Nilai $\mathrm{p}=0,001^{*}$} \\
\hline \multicolumn{4}{|c|}{ 2. Active Learning Strategies } \\
\hline Pre & $78,2(12,4)$ & 80,0 & $46,6-100$ \\
\hline Post & $84,5(14,1)$ & 86,7 & $26,7-100$ \\
\hline \multicolumn{4}{|c|}{ Perbandingan Pre Vs Post Nilai $\mathrm{p}=0,005^{*}$} \\
\hline \multicolumn{4}{|c|}{ 3. SPKence Leraning V alue } \\
\hline Pre & $86,1(15,4)$ & 88,9 & $55,6-100$ \\
\hline Post & $94,6(9,9)$ & 100,0 & $66,7-100$ \\
\hline \multicolumn{4}{|c|}{ Perbandingan Pre Vs Post Nilai $\mathrm{p}=0,001^{*}$} \\
\hline \multicolumn{4}{|c|}{ 4. Performance Goal } \\
\hline Pre & $74,7(11,0)$ & 75,0 & $50,0-100$ \\
\hline Post & $83,0(12,7)$ & 83,3 & $50,0-100$ \\
\hline \multicolumn{4}{|c|}{ Perbandingan Pre Vs Post Nilai $\mathrm{p}=0,001^{*}$} \\
\hline \multicolumn{4}{|c|}{ 5. Achierment Goal } \\
\hline Pre & $81,9(13,4)$ & 86,7 & $53,3-100$ \\
\hline Post & $87,6(11,5)$ & 86,7 & $60,0-100$ \\
\hline \multicolumn{4}{|c|}{ Perbandingan Pre Vs Post Nilai $\mathrm{p}<0,019^{*}$} \\
\hline \multicolumn{4}{|c|}{ 6. Learning Environment Stimulation } \\
\hline Pre & $80,1(12,5)$ & 80,1 & $53,3-100$ \\
\hline Post & $90,1(9,9)$ & 93,3 & $60,0-100$ \\
\hline \multicolumn{4}{|c|}{ Perbandingan Pre Vs Post Nilai $\mathrm{p}=0,001^{*}$} \\
\hline \multicolumn{4}{|c|}{ Gabungan/perbandingan } \\
\hline Pre & $80,1(8,7)$ & 82,1 & $60,2-100$ \\
\hline Post & $87,6(8,3)$ & 88,5 & $56,4-100$ \\
\hline
\end{tabular}

Ket : *) Uji Wilcoxon 
Dari tabel 1 terlihat bahwa terjadi peningkatan nilai rerata refleksi diri mahasiswa sebelum dan setelah penggunaan e-monif dari 74,9 menjadi 80,5 $(\mathrm{p}<0,005)$. Artinya, terdapat peningkatan refleksi diri mahasiswa setelah penggunaan e-monif.

Pada tabel 2 terlihat bahwa peningkatan nilai rerata motivasi diri mahasiswa sebelum dan setelah penggunaan e-monif dari 80,1 menjadi 87,6 ( $\mathrm{p}<0,005)$. Artinya, terdapat peningkatan motivasi belajar mahasiswa setelah penggunaan e-monif.

Dari Tabel 3 tersebut menunjukkan terdapat peningkatan nilai skor rerata hasil belajar mahasiswa sebelum dan setelah penggunaan e-monif dari 61,8 menjadi 68,4 $(p<0,005)$. Artinya, terdapat peningkatan hasil belajar mahasiswa setelah penggunaan e-monif.

Tabel 3. Perbandingan Hasil Belajar Mahasiswa Sebelum dan Setelah Penggunaan E-Monif

\begin{tabular}{lccc}
\hline Hasil belajar & \multicolumn{2}{c}{ Perbandingan } & Nilai p \\
\hline $\bar{x}(\mathrm{SD})$ & $61,8(6,9)$ & $68,4(9,5)$ & $0,000^{*}$ \\
Median & 60,0 & 65,0 & \\
Rentang & $47,5-77,5$ & $52,5-97,5$ & \\
\hline
\end{tabular}

Ket : *) Uji Wilcoxon

\section{PEMBAHASAN}

Berdasarkan hasil penelitian pada Tabel 1 diperoleh hasil bahwa skor rerata Refleksi diri mahasiswa mengalami kenaikan dari sebelum dan setelah penggunaan e-monif yaitu dari 74,9 menjadi 80,5 ( $\mathrm{p}<0,05)$. Artinya terlihat ada peningkatan yang bermakna antara refleksi diri setelah penggunaan e.monif pada kegiatan PBL II tersebut.

Refleksi diri merupakan sebuah respon penilaian diri yang ditimbulkan dari hasil pengalaman dan perenungan kegiatankegiatan, pengalaman ataupun kejadiankejadian yang dialami di masa lampau. Kemudian diikuti dengan proses intrspeksi diri yang bertujuan untuk membangun rencana masa depan menjadi tenaga kesehatan yang lebih baik, sehingga mengurangi munculnya ketidaksesuaian antara harapan dan kenyataan (Mengurangi adanya gap) (Oktaria D, 2015).

Refleksi diri bisa dilakukan oleh siapa saja yang memiliki tujuan untuk memperbaiki rencana agar sesuai dengan tujuan atau hasil yang diharapkan. Tetapi tidak jarang, seseorang tidak menyadari telah melakukan refleksi diri (Shafira NNA, 2015). Memiliki refleksi diri pada seorang tenaga kesehatan sangat diperlukan. Dikarenakan sebagai lulusan tenaga kesehatan khusunya bidan harus mampu mempraktikkan proses 
pembelajaran yang terus menerus sesuai dengan perkembangan ilmu dan pengetahuan dan mampu menyadari kinerja profesionalitas diri dan mengidentifikasi kebutuhan belajar untuk mengatasi kelemahan. Mengetahui kelemahan diri berdasarkan penilaian pengalaman dan dapat menyusun rencana perubahan dalam diri merupakan poin penting bagi mahasiswa. Melalui proses seperti itu diharapkan akan menjadi terbiasa dengan sikap refleksi diri yang dipakai setiap hari setelah menjadi seorang tenaga kesehatan (Koole et.al, 2012)

Pada sebuah artikel yang telah dibuat yang berjudul Refleksi diri sebagai salah satu metode pembelajaran di Fakultas kedokteran dijelaskan bahwa refleksi diri dalam konteks pendidikan dapat disadari sebagai proses atau tindakan untuk melihat kembali ke masa lampau dengan tujuan untuk memproses pengalaman yang didapat sehingga dapat diinterpretasikan atau dianalisis.Refleksimerupakan suatu proses metakognitf yang terjadi sebelum, selama dan sesudah situasi tertentu dengan tujuan untukmengembangkan pemahaman yang lebih baik mengenai diri sendiri dan situasi yang dihadapi sehingga ketika dimasa depan menemui situasi serupa dapat bertindak lebih baik.(Oktaria D, 2015).

Menurut atikel yang terkait dengan perubahan tahun pertama pada mahasiswa kedokteran, dijelaskan bahwa refleksi diri merupakan salah satu dari proses metakognisi yang penting dalam pendidikan kesehatan dikarenakan mahasiswa tidak bisa bergantung sepenuhnya kepada para pembimbing ataupun pendidiknya. Mahasiswa harus mampu untuk merencanakan dan memanfaatkan pengetahuan dalam berbagai tugas. Mahasiswa yang memiliki daya metakognisi yang rendah akan cenderung menghadapi masalah karenamereka tidak akan dapat menentukan tugas atau masalah yang dihadapi, tidak mampu untuk merencanakan tindakan atau sikap yang akan diambil, tidak dapat menilai atau memantau kinerja mereka sendiri, sehingga mereka akan mengalami kesulitan dalam proses pembelajaran (Hong WH et.al, 2015).

Proses metakognitif yang dimiliki oleh mahasiswa tenaga kesehatan akan mendorong mahasiswa denganlebih baik dalam menggunakan pengetahuan medis dasar untuk memberikan penilaian klinis, berpikir kritis, danmelakukan refleksi diri. (Purnomo SR, 2016). Peneliti berpendapat bahwa kenaikan nilai refleksi diri mahasiswa setelah penelitian merupakan hasil dari adanya umpan balik yang korektif dan efektif melalui e-monif yang diberikan pembimbing untuk mengevaluasi dan 
memotivasi mahasiswa dalam proses pembelajaran, sehingga mendorong mahasiswauntuk lebih baik dalam meningkatkan hasil belajarnya.

Berdasarkan hasil penelitian yang terlihat pada Tabel 2 tersebut, diketahui peningkatan nilai rerata motivasi diri mahasiswa sebelum dan setelah penggunaan e-monif dari 80,1 menjadi 87,6 $(\mathrm{p}<0,005)$. Artinya, terdapat peningkatan motivasi belajar mahasiswa setelah penggunaan e-monif. Motivasi sangat erat hubungannya dengan tujuan atau keinginan yang akan dicapai seseorang. Disadari ataupun tidak disadari, untukmencapai satu tujuan itu perlu adanya aksi yang dilakukan ataupun perbuatan yang direalisasikan, sedangkan yang menjadi penyebab seseorang melakukan atau merealisasikan suatu perbuatan (Sulisworo D, (t.t)). Motivasi adalah suatu dorongan atau daya penggerak yang muncul dalam diri manusia untuk mencapai tujuan. (Syah M, 2012)

Peneliti berpendapat bahwa pada diri seorang peserta didik atau mahasiswa muncul adanya Motivasi belajar. Motivasi tersebut muncul sebagai bentuk dorongan atau daya penggerak dalam diri mahasiswa secara psikologis untuk memunculkan keinginan untuk belajar, memastikan proses belajar dilakukan secara terus menerus dan memberikan arahan pada kegiatan belajar yang dilaksanakan demi tercapainya tujuan pembelajaran. Motivasi sangat berperan penting dalam membangkitkan gairah belajar sehingga mahasiswa yang memiliki motivasi kuat memiliki energi banyak untuk melaksanakan kegiatan belajar.

Sumber motivasi belajar itu berasal dari dua unusur yaitu motivasi instrinstik (dari dalam diri) dan ekstrinsik (dari luar diri). Pertama motivasi instrinsik, yaituunsurunsur ataupun keadaan yang berasal dari dalam diri mahasiswa itu sendiri yang dapat mendorong atau memacu diri untuk melakukan kegiatan belajar. Misalnya rasa suka pada satu materi atau kebutuhannya pada materi tersebut yang berguna untuk jenjang karir dia dimasa yang akan datang. Kedua, motivasi Ekstrinsik adalah unsurunsur ataupun keadaan yang muncul atau datangnya dariluar diri mahasiswa yang dapat memacu dan mendorong mahasiswa untuk melakukan kegiatan belajar. Misalnya mendapatkan pujian, mendapatkan hadiah atau imbalan, penghargaan, tata tertib sekolah, dan hallain yang bersumber dariluar diri mahasiswa yang mampu mendorong mahasiswa untuk melakukan kegiatan belajar. Kehilangan motivasi baik kehilangan motivasi internal ataupun eksternal dapat meneybabkan hialangnya semangat mahasiswa dalam mengikuti kegiatan pembelajaran baik dilingkup institusi pendidikan misalnya sekolah ataupun di lingkungan rumah. Dalam pendekatan secara kognitif, motivasi 
instrinsik lebih besar pengaruhnya dibandingkan yang berasal dari ekstrinsik (Syah M, 2012)

Pada hasil penelitian yang telah dilakukan oleh Sulisworo terkait dengan pengaruh penggunaan e-learning dengan motivasi belajar didapatkan hasil bahwa terdapat pengaruh yang signifikan terhadap motivasi yang dimilikioleh peserta didik (Sulisworo $\mathrm{D}$, (t.t)). Hal ini didukung oleh penelitian yang dilakukan oleh Ermiza yang didapatkan bahwa banyak faktor yang dpat memengaruhi motivasi peserta didik dan salah satunya yaitu dari media pembelajaran (Ermiza, 2017). Peneliti berpendapat bahwa kenaikan motivasi belajar mahasiswa tersebutsangat dipengaruhi oleh faktor instrinsik dan ekstrinsik yang ada pada diri mahasiswa. Tetapi faktor instrinstik memiliki kendali yang lebih besar dalam menumbuhkan motivasi dalam diri seseorang.

Berdasarkan hasil penelitian dari tabel 3 tersebut menunjukan adanya kenaikan rerata hasil belajar mahasiswa sebelum dan setelah penggunaan e-monif dari 61,8 menjadi 68,4. Berdasarkan dari hasil uji wilcoxon terlihat ada perbedaan yang signifikan pada hasil belajar sebelum dan setelah penggunaan e-monif $(p<0,05)$.

Hasil belajar mahasiswa didapatkan melalui pemberian evaluasi yang bertujuan untuk mengetahui sejauh manakah proses belajar dan pembelajaran itu berlangsung secara efektif dan telah sesuai dengan tujuan pembelajaran dari masing-masing-masing mata pelajaran atau mata kuliah (Syah M, 2012). Efektivitas proses belajar tersebut akan tampak pada kemampuan mahasiswa menguasai materi pelajaran. Evaluasi hasil pembelajaran atau evaluasi hasil belajar di Perguruan Tinggi memiliki berbagai macam alat ukur yang mampu menilai hasil belajar. Salah satunya antara lain menggunakan tes untuk melakukan pengukuran hasil belajar sebagai prestasi belajar (Pusdiknakkes, 2010).

Ada bebrapafaktor yang memengaruhi hasil belajar yaitu Faktor dari dalam dan faktor dari luar.Pertama, faktor dari dalam (faktor internal) meliputi faktor jasmaniah (faktor kesehatan, cacat tubuh), faktor psikologis (intelegensi, perhatian, minat, bakat, motif, kematangan dan kesiapan), dan faktor kelelahan.Kemudian faktor dari luar (faktor eksternal), faktor eksternal dapat dikelompokkan menjadi tiga yaitu faktor keluarga, faktor sekolah dan masyarakat. Faktor-faktor tersebut yang memengaruhi pencapaian hasil belajar ataupun yang dapat memengaruhi proses pembelajaran yang dilalui oleh mahasiswa (Syah M, 2012)

Berdasarkan hasil penelitian tentang pengembangan model pembelajaran $e$ learning berbasis web diketahui bahwa hasil penelitian didapatkan bahwa adanya peningkatan hasil belajar mahasiswa setelah 
penggunaan e-learning berbasis web.(Wijaya M, 2012). E-lerning merupakan suatu proses pembelajaran yang menggunakan teknologi informasi yang memudahkan mahasiswa dan pendidik/pembimbing dalam proses pembelajaran.

Memanfaatkan perkembangan ilmu pengetahuan dan teknologi informasi saat ini sangat penting. Sebab terbukti bahwa dengan menggunakan teknologi informasi, efektifitas dan efisiensi melakukan sebuah proses lebih cepat untuk tercapai (Ramdani $R, 2014)$.

Peneliti berpendapat bahwa penggunaan teknologi dalam pembelajaran dimasa saat ini sudah sangat dibutuhkan untuk membantu proses pembelajaran. Seperti halnya pada penelitian ini, penggunaan emonif yang bertujuan untuk memfasilitasi diskusi dalam pemberian umpan balik yang korektif dan efektif pada mahasiswa mampu meningkatkan refleksi diri mahasiswa, motivasi belajar dan hasil belajar.

\section{KESIMPULAN}

Terdapat peningkatan refleksi diri, motivasi dan hasil belajar mahasiswa DIII Kebidanan setelah penggunaan emonitoring interaktif .

\section{Ucapan Terima Kasih}

Kepada Ketuadan mahasiswa STIKes Muhammadiyah Cirebon dan seluruh pihak yangtelah terlibat dan mendukung terlaksananya penelitian ini.

\section{REFERENSI}

AIPKIND (2018) Panduan Pengembangan Kurikulum Pendidikan Diploma III Kebidanan. 1. Jakarta: Asosiasi Pendidikan Kebidanan Indonesia (AIPKIND)

BPKPPKKR.(2010). Bahan Materi : Pertemuan Koordinasi Pengelola Penyelenggara DIKNAKES. Jakarta: Badan PPSDM Kesehatan Pusat PendidikanTenaga Kesehatan Kementrian Kesehatan Republik Indonesia

Ermiza. (2017).Faktor-Faktor yang Berhubungan Dengan Motivasi Belajar Mahasiswa Semester VI di Program Studi DIII Kebidanan STIKes Fort De Kock BukittinggiTabun 2013. Jurnal Maternity and Neonatal2:3.

Hong WH VJ, Daniel EGS, Sim JH. (2015). Thinking about thinking: changes in first-year medical students' metacognition and its relation to performance. Medical Education Online20:1.

Kurniawati, et.al.(2014). Hubungan Karakteristik Pembimbing Klinik Dengan Keterampilan Klinik Asuban Persalinan Normal Pada Mahasiswa Program Diploma III Kebidanan. IJEMC 1:8.

Koole S et.al.(2012). Does reflection have an effect upon case-solving abilities of undergraduate medical students?BMC Medical Education.12:1.

Levy LS SP, Willeford KS, Barnum MG, Guyer MS, Gardner G, et al. (2009).Clinical instructor characteristics, behaviors and skills in allied health care settings: A literature review. Athletic Training Education Journal 4:1.

Mariana G.H. (1998). Provide Feedback In Medical Education. JGIM. 13:10. 
Molloy E. (2013) Feedback models For Learning, Teaching And Performance. Education and technology Communication Research 4:1.

Nurhasanah et.al. (2014). Pengarub Penerapan SistemMentor Terbadap Pencapaian keterampilan Klinik Asuban Persalinan Mabasiswa Akademi Kebidanan Mubammadiyah Cirebon. IJEMC 1:1.

Oktaria D. (2015).Refleksi Diri Sebagai Salah Satu Metode Pembelajaran di Fakultas Kedokteran. Lampung: FK Universitas lampung

Purnomo TN S. (2016). Metacognition Process Characteristics Of The Students In Solving Mathematics Problem. IOSR Journal of Research \&Method in Education (IOSR-JRME)6:5.

Poltekkes Bandung. (2003).Laporan Penilaian Program Preseptor Mentor Pada Program Studi Kebidanan Poltekkes Kesehatan Bandung. Bandung: Politeknik Kesehatan Bandung.

Ramdani R. (2014). E-Learning Sebagai Media Pelengkap Pembelajaran Konvensional
Pada Pokok Bahasan Besaran dan Satuan. Prosiding Pertemuan Ilmiah XXVIII HFI Jateng \& DIY 4:1.

Sari RKS, Qusuma IF, (2015).Peran Pembimbing Klinik dan Pelaksanaan Keselamatan Pasien Oleh Mahasiswa Profesi Ners.Unissula Nursing Conference; Semarang. Semarang: Unissula Press.

Shafira NNA. (2015). Penerapan Reflekesi diri dan Self Evaluation Sebagai Keterampilan dasar Dalam Meningkatkan Profesionalisme Pada mahasiswa kedokteran. JMJ 3:1.

Sulisworo SPA. (t.t) Dampak Pembelajaran E-Learning Terbadap Motivasi Pada Pembelajaran Fisika Di Sekolah Kejuruan. Berkala Fisika Indonesia

Syah M. (2012). Psikologi Pendidikan Dengan Pendekatan Baru. Bandung: Rineka Cipta.

Wijaya M. (2012). Pengembangan Model Pembelajaran e-Learning Berbasis Web dengan Prinsip e-Pedagogy dalam Meningkatkan Hasil Belajar.Jurnal Pendidikan Penabur 19:2. 